\title{
Is Cardiopulmonary Fitness Level a Risk Factor in Young Saudi Females?
}

\author{
Lubna I. Al Asoom, PhD \\ Department of Physiology, College of Medicine, University of Dammam \\ Dammam, Saudi Arabia
}

\section{Correspondence \\ Dr. Lubna I. Al Asoom \\ P.O. Box 1982, Dammam 31441, Saudi Arabia \\ e.M: lasoom@uod.edu.sa \\ Submission: 4 Apr. 2015 \\ Accepted: 25 May 2015}

\section{Citation}

Al Asoom LI. Is cardiopulmonary fitness level a risk factor in young Saudi females? JKAU Med Sci 2015; 22 (3): 19-28. DOI: 10.4197/Med. 22.3 .3

\begin{abstract}
Low physical fitness is one of the all-cause mortality risk factors. This study aims to estimate cardiopulmonary fitness $\left(\mathrm{VO}_{2} \mathrm{max}\right)$ in young Saudi females and correlate it to anthropometric and hemodynamic parameters. Forty-eight young Saudi females completed an exercise stress test until exhaustion. Basal and maximum pulse rate, arterial blood pressure, $\mathrm{VO}_{2}$ max and other anthropometric data were measured. The population was divided into low and high $\mathrm{VO}_{2}$ max groups and a comparison was run using student t-test. Correlation was tested between $\mathrm{VO}_{2}$ max and other measured parameters. The mean $\mathrm{VO}_{2}$ max of the sample population was low $(33.6 \pm 8.2 \mathrm{~mL} /$ ( $\mathrm{kg} \cdot \mathrm{min}$ ) with $37.5 \%$ exhibiting fair to very poor $\mathrm{VO}_{2}$ max value. The low $\mathrm{VO}_{2}$ max group was characterized by higher body mass index, exercise diastolic and mean arterial blood pressure when compared to normal $\mathrm{VO}_{2}$ max group, indicating a strong negative correlation. This study revealed a low cardiopulmonary fitness in young Saudi females and showed a strong association between $\mathrm{VO}_{2}$ max and increased body fat and maximum exercise diastolic blood pressure. These findings provide reliable indicators of increased all-cause mortality risk in young Saudi females and increase the urgency of prompt action.
\end{abstract}

\section{Keywords}

Cardiopulmonary fitness; $\mathrm{VO}_{2}$ max; Bruce protocol; Exercise stress test; Young female

\section{Introduction}

hysical inactivity is one of the major risk factors that threaten the public health ${ }^{[1]}$. Recent epidemiological studies demonstrated a significant impact of moderate physical activity on lowering the incidence of all vascular diseases including coronary vascular, cerebrovascular and thromboembolic diseases $^{[2]}$.

Few studies were performed in Saudi Arabia aimed at estimating the extent of physical inactivity in our population. Most of these studies utilized a physical activity questionnaire for the assessment of physical fitness. In a study performed on 1064 subjects of both sexes across a wide range of age (15-78 years), there was a high incidence of physical inactivity that is more obvious in females than males ${ }^{[3]}$. It is also found that the engagement in frequent exercise activities about three times per week diminishes early in life more commonly in females compared to males $(45.6 \%$ male engagement versus $33.7 \%$ female engagement) ${ }^{[4]}$.

Most of the studies performed in our country focused on males, specifically young teenagers 
and children, whether sedentary or athletic ${ }^{[5,6]}$. Concurrently, we believe that females in Saudi Arabia are more prone to an extreme reduction of physical activity due to cultural beliefs, city structure, and family responsibilities.

Although using a standardized physical activity assessment questionnaire helps in providing an insight to the extent of the physical inactivity, some studies revealed an overestimate of physical fitness using the questionnaire, and hence an amelioration of the encountered health hazard ${ }^{[7]}$. The most accurate and reliable method for estimating physical fitness is using the standard cardiopulmonary exercise testing ${ }^{[8]}$. Data collected from different populations revealed differences in the standard values and showed consistently lower female parameters ${ }^{[9,10]}$.

Therefore, in the current study we aim to evaluate cardiopulmonary fitness in young Saudi females by estimating $\mathrm{VO}_{2}$ max using exercise stress test, compare the finding with other population fitness values, and find the possible correlation of cardiopulmonary fitness represented by $\mathrm{VO}_{2}$ max with anthropometric and hemodynamic parameters.

\section{Subjects and Method}

The current cross-sectional study was approved by the Institutional Review Board (IRB) at University of Dammam (IRB certificate number 2015-01-065) according to the revision of Declaration of Helsenki ${ }^{[11]}$.

A sample of young Saudi college female students from different colleges of the University of Dammam was recruited on a voluntary basis following the general announcement.

Those who were pregnant or lactating within the last two years were excluded. Any subject with a history of smoking or disease that is considered contraindicative of stress exercise testing such as cardiovascular, respiratory, hematological or musculoskeletal disorders was excluded. Forty-eight female students were found eligible to enter the study. The study procedure was explained carefully to the subjects and they signed a written informed consent. The study examinations and tests were performed in the physiology laboratory, College of Medicine, University of Dammam. All tests were performed in the period from October 2014 to April 2015 from 9 a.m.-1 p.m., excluding exam periods.

\section{Anthropometric Measurement}

Weight was determined for each subject using a portable platform scale with an accuracy within $0.1 \mathrm{~kg}$. Height was assessed using a cm scale with an accuracy to the nearest $0.25 \mathrm{~cm}$. Body mass index (BMI) was calculated using the formula (weight $\mathrm{kg} /$ height $\mathrm{m}^{2}$ ). Determinants of central obesity were also assessed, including waist (at the level of umbilicus using nonstretchable measuring tape while wearing light clothes) and hip circumference (determined as the largest diameter of the hip) and the ratios waist/hip and waist/height were calculated. These measurements were performed before the subject performed the cardiopulmonary exercise testing (CPET).

\section{Cardiopulmonary Exercise Testing}

A clear explanation of the procedure of CPET was introduced to the subject before starting the test. The subjects were encouraged to perform at maximum effort, however the participant had the right to stop the test when fatigued.

Baseline pulse rate, oxyhemoglobin $\left(\mathrm{HbO}_{2}\right)$ saturation, arterial blood pressure (systolic and diastolic) and electrocardiograph (ECG) were recorded.

Continuous monitoring of pulse rate, $\mathrm{HbO}_{2}$ saturation, arterial blood pressure and ECG was performed during the exercise procedure and carefully observed by an expert.

Each subject performed the treadmill Bruce protocol $^{[12]}$ using exercise physiology laboratory (ADInstruments, Bella Vista NSW, Australia). In the Bruce protocol, the subject starts with speed of $1.7 \mathrm{mph}$ at a $10 \%$ grade. Consequently, both speed and inclination are increased every three minutes until exhaustion.

Simultaneously the increment in pulse rate was observed and compared to the calculated maximal heart rate of the subject as predicted by age, using the formula:

Predicted maximum heart rate $=208-0.7 \times$ age $^{[13]}$.

An achievement of $85 \%$ of the predicted maximum heart rate or above was set as the criterion of reaching maximum effort.

Maximal oxygen consumption ( $\mathrm{V}$ - volume, $\mathrm{O}_{2}$ oxygen, max - maximum $\left(\mathrm{VO}_{2}\right.$ max)) was estimated 
from the total time until exhaustion $\mathrm{T}$ ( $\mathrm{min}$ ) using the following formula (Pollock Formula)

$$
\mathrm{VO}_{2} \max =4.38 \times \mathrm{T}-3.9^{[14]}
$$

Mean arterial blood pressure was determined using the following formula:

MAP $=$ Diastolic blood pressure+ $1 / 3$ (systolic blood pressure - diastolic blood pressure) ${ }^{[15]}$

\section{Statistical Analysis}

IBM SPSS Statistics for Windows, Version 20 (IBM Corp., Armonk, NY USA) was used to analyze the data. Maximum oxygen cosumption values were normally distributed based on the results of Shapiro-Wilk and Kolmogorov-Smirnov tests, therefore, parametric tests were used for comparison. All data were expressed as Mean \pm SD.

The Bivariate (Pearson) Correlation was used to find out the possible correlation of $\mathrm{VO}_{2}$ max, anthropometric and hemodynamic data. Linear regression models were generated when a significant correlation was found. The level of significance was set at $P$-value $<0.05$

\section{Results}

Descriptive data for all participants, including age, anthropometric, exercise and hemodynamic parameters, are shown in Tables 1 and 2. All CPETs ran uneventfully, no signs of ischemia or arrhythmias were detected in ECG at baseline or during the exercise test. A comparison of hemodynamic data including heart rate, blood pressure and $\mathrm{HbO}_{2}$ saturation percentage revealed significantly higher maximum exercise heart rate, systolic and mean arterial blood pressure vs the corresponding resting values (Table 2 ).
The participants were classified based on their $\mathrm{VO}_{2}$ max value into six categories according to the specification of the physical fitness specialist certification manual[16] (Table 3): $17 \%$ very poor $\left(\mathrm{VO}_{2}\right.$ $\max <23.6 \mathrm{~mL} /(\mathrm{kg} \cdot \mathrm{min}) ; 17 \%$ poor $\left(\mathrm{VO}_{2} \max =23.6-\right.$ $28.9 \mathrm{~mL} /(\mathrm{kg} \cdot \mathrm{min}) ; 4 \%$ fair $\left(\mathrm{VO}_{2} \max =29.0-32.9 \mathrm{~mL} /\right.$ (kg.min); $17 \%$ good $\left(\mathrm{VO}_{2} \max =33.0-36.9 \mathrm{~mL} /(\mathrm{kg} \cdot \mathrm{min})\right.$; $27 \%$ excellent $\left(\mathrm{VO}_{2} \max =37.0-41.0 \mathrm{~mL} /(\mathrm{kg} \cdot \mathrm{min}) ; 19 \%\right.$ superior $\left(\mathrm{VO}_{2} \max >41.0 \mathrm{~mL} /(\mathrm{kg} \cdot \mathrm{min})\right.$.

The participants were then divided into two main groups to simplify comparison. The first group includes very poor to fair categories, considered the low $\mathrm{VO}_{2}$ max group, and accounts for $37.5 \%$ of the sample. The second group includes good to superior categories, considered the high $\mathrm{VO}_{2}$ max group, and accounts for $62.5 \%$ of the sample. Using independent samples "student's" $t$ test, the anthropometric and hemodynamic data were compared and revealed significantly higher values for weight, BMI, waist/ height ratio (Table 4), last diastolic blood pressure, and mean arterial blood pressure (Table 5) in the low $\mathrm{VO}_{2}$ max group compared to the high $\mathrm{VO}_{2}$ max group. Conversely, $\mathrm{VO}_{2} \max$, and time until exhaustion were lower in the low $\mathrm{VO}_{2}$ max group (Table 5).

Maximum oxygen cosumption showed a significant negative correlation with anthropometric data including body weight $(r=(-0.554, P=0.001)$, BMI $(r=-0.535, P=0.001)$, waist $(r=-0.497, P=0.001)$, and hip circumference $(r=-0.519, P=0.001)$ (Fig. 1). Similarly, a negative correlation was found between $\mathrm{VO}_{2}$ max and last diastolic blood pressure $(r=-0.304, P$ $=0.036)$ and mean arterial blood pressure $(r=-0.325, P$ $=0.024$ ) (Fig. 2). Correlation of $\mathrm{VO}_{2}$ max with age was insignificant $(r=-0.009, P=0.950)$.

Table 1. Age, anthropometric and exercise test data of young Saudi female college students $(n=48)$

\begin{tabular}{|l|c|c|}
\hline \multicolumn{1}{|c|}{ Parameters } & Mean \pm SD & Min-Max \\
\hline Age (years) & $20.58 \pm 1.90$ & $19.00-27.00$ \\
\hline Body weight $(\mathrm{kg})$ & $59.26 \pm 16.36$ & $37.20-115.80$ \\
\hline Height $(\mathrm{cm})$ & $158.65 \pm 7.50$ & $143.50-176.50$ \\
\hline Body mass index $\left(\mathrm{kg} / \mathrm{m}^{2}\right)$ & $23.34 \pm 5.15$ & $16.81-38.91$ \\
\hline Waist circumference $(\mathrm{cm})$ & $71.90 \pm 11.23$ & $59.00-116.00$ \\
\hline Hip circumference $(\mathrm{cm})$ & $97.77 \pm 12.12$ & $78.00-133.00$ \\
\hline Waist/hip ratio $(\mathrm{W} / \mathrm{H})$ & $0.73 \pm 0.05$ & $0.63-0.89$ \\
\hline Waist/height ratio $(\mathrm{W} / \mathrm{S})$ & $0.45 \pm 0.06$ & $0.36-0.67$ \\
\hline V0 max $(\mathrm{mL} /(\mathrm{kg} \cdot \mathrm{min}))$ & $32.00 \pm 8.12$ & $13.38-44.01$ \\
\hline Time of exercise till exhaustion $(\mathrm{min})$ & $8.40 \pm 1.87$ & $4.21-11.14$ \\
\hline
\end{tabular}

$\mathrm{VO}_{2}$ max: Maximum oxygen consumption 
Table 2. Hemodynamic parameters of young Saudi female college students ( $n=48)$.

\begin{tabular}{|l|c|c|c|}
\hline \multicolumn{1}{|c|}{ Hemodynamic Parameter } & Resting & Last & Significance \\
\hline \multirow{2}{*}{ Systolic blood pressure (mmHg) } & $120.10 \pm 12.27$ & $144.96 \pm 31.47$ & 0.0001 \\
\hline \multirow{2}{*}{ Diastolic blood pressure (mmHg) } & $(98.00-150.00)$ & $(102.00-247.00)$ & 0.054 \\
\hline \multirow{2}{*}{ Mean arterial blood pressure (mmHg) } & $\begin{array}{c}78.70 \pm 7.29 \\
64.00-92.00\end{array}$ & $\begin{array}{c}76.81 \pm 7.30 \\
62.00-93.00\end{array}$ & 0.0001 \\
\hline \multirow{2}{*}{$\mathrm{HbO}_{2}$ saturation (\%) } & $92.51 \pm 8.13$ & $99.54 \pm 12.27$ & 0.091 \\
\hline \multirow{2}{*}{ Heart rate (beats/min) } & $76.00-108.67$ & $78.00-134.00$ & 0.0001 \\
\hline
\end{tabular}

Data expressed as mean \pm standard deviation. Comparison between each pair of variables was made using paired "student's" $t$ test. $\mathrm{HbO}_{2}=$ Oxyhemoglobin.

Table 3. Classification of $\mathrm{VO}_{2} \max ^{[16]}$

\begin{tabular}{|l|c|}
\hline \multicolumn{1}{|c|}{$\mathrm{VO}_{2}$ max Category } & Number (\%) of Participants \\
\hline Very Poor $\left(\mathrm{VO}_{2} \mathrm{max}<23.6 \mathrm{~mL} /(\mathrm{kg} \cdot \mathrm{min})\right.$ & $8(17.00 \%)$ \\
\hline Poor $\left(\mathrm{VO}_{2} \mathrm{max}=23.6-28.9 \mathrm{~mL} /(\mathrm{kg} \cdot \mathrm{min})\right.$ & $8(17.00 \%)$ \\
\hline Fair $\left(\mathrm{VO}_{2} \mathrm{max}=29.0-32.9 \mathrm{~mL} /(\mathrm{kg} \cdot \mathrm{min})\right.$ & $2(4.00 \%)$ \\
\hline Good $\left(\mathrm{VO}_{2} \mathrm{max}=33.0-36.9 \mathrm{~mL} /(\mathrm{kg} \cdot \mathrm{min})\right.$ & $8(17.00 \%)$ \\
\hline Excellent $\left(\mathrm{VO}_{2} \mathrm{max}=37.0-41.0 \mathrm{~mL} /(\mathrm{kg} \cdot \mathrm{min})\right.$ & $13(27.00 \%)$ \\
\hline Superior $\left(\mathrm{VO}_{2} \mathrm{max}>41.0 \mathrm{~mL} /(\mathrm{kg} \cdot \mathrm{min})\right.$ & $9(19.00 \%)$ \\
\hline $\mathrm{VO}_{2}$ max: Maximal oxygen consumption &
\end{tabular}

Table 4. Comparison of anthropometric data between subjects with low and high $\mathrm{VO}_{2}$ max.

\begin{tabular}{|c|c|c|c|}
\hline Parameters & $\begin{array}{c}\text { Low V0 } 2 \text { max } \\
(n=18)\end{array}$ & $\begin{array}{l}\text { High V0 } 2 \text { max } \\
(n=30)\end{array}$ & P-value \\
\hline Age (years) & $20.39 \pm 1.69$ & $20.70 \pm 2.04$ & 0.588 \\
\hline Weight (Kg) & $69.04 \pm 20.28$ & $53.39 \pm 9.87$ & 0.006 \\
\hline Height $(\mathrm{cm})$ & $161.00 \pm 6.26$ & $157.24 \pm 7.91$ & 0.093 \\
\hline $\mathrm{BMl}^{\mathrm{a}}\left(\mathrm{kg} \cdot \mathrm{m}^{2}\right)$ & $26.33 \pm 6.08$ & $21.55 \pm 3.52$ & 0.006 \\
\hline Waist Circumference $(\mathrm{cm})$ & $78.11 \pm 14.14$ & $68.17 \pm 6.98$ & 0.011 \\
\hline Hip Circumference (cm) & $104.39 \pm 14.12$ & $93.80 \pm 8.81$ & 0.002 \\
\hline Waist/Hip circumference & $0.74 \pm 0.05$ & $0.72 \pm 0.06$ & 0.288 \\
\hline Waist/Height ratio & $0.48 \pm 0.08$ & $0.43 \pm 0.05$ & 0.018 \\
\hline
\end{tabular}

Data expressed as mean \pm standard deviation. Comparison between the two groups was made using unpaired "student's" $t$ test. $\mathrm{BMI}=$ Body mass index; $\mathrm{VO}_{2}$ max: Maximal oxygen consumption

Table 5. Comparison of exercise test and hemodynamic parameters between subjects with low and high $\mathrm{VO}_{2}$ max.

\begin{tabular}{|c|c|c|c|}
\hline Parameters & $\begin{array}{c}\text { Low V0 }{ }_{2} \text { max } \\
(n=18)\end{array}$ & $\begin{array}{l}\text { High V0 } 2 \text { max } \\
\quad(n=30)\end{array}$ & $P$-value \\
\hline $\mathrm{V}_{2} \max \mathrm{mL} /(\mathrm{kg} \cdot \min )$ & $24.10 \pm 4.40$ & $39.30 \pm 2.80$ & 0.001 \\
\hline Time of exercise till exhaustion (min) & $6.24 \pm 1.00$ & $9.69 \pm 0.67$ & 0.001 \\
\hline Resting systolic blood pressure (mmHg) & $123.78 \pm 11.85$ & $117.90 \pm 12.18$ & 0.108 \\
\hline Last systolic blood pressure $(\mathrm{mmHg})$ & $155.94 \pm 37.53$ & $138.37 \pm 25.68$ & 0.060 \\
\hline Resting diastolic blood pressure (mmHg) & $80.56 \pm 7.16$ & $77.60 \pm 7.26$ & 0.177 \\
\hline Last diastolic blood pressure $(\mathrm{mmHg})$ & $79.72 \pm 6.70$ & $75.07 \pm 7.20$ & 0.031 \\
\hline Baseline mean arterial blood pressure & $94.96 \pm 7.23$ & $91.03 \pm 8.40$ & 0.106 \\
\hline Last mean arterial blood pressure & $105.17 \pm 13.02$ & $96.17 \pm 10.64$ & 0.012 \\
\hline Resting $\mathrm{HbO}_{2}$ saturation $\%$ & $97.72 \% \pm 2.99 \%$ & $97.97 \% \pm 2.92 \%$ & 0.437 \\
\hline Last $\mathrm{Hb}_{2}$ saturation $\%$ & $96.39 \% \pm 7.29 \%$ & $95.43 \% \pm 6.67 \%$ & 0.645 \\
\hline Resting heart rate (beats/min) & $107.39 \pm 12.62$ & $101.37 \pm 14.28$ & 0.147 \\
\hline Last heart rate (beats/min) & $179.11 \pm 8.20$ & $178.03 \pm 9.39$ & 0.689 \\
\hline
\end{tabular}

Data expressed as mean \pm standard deviation. Comparison between the two groups was made using unpaired "student's" $t$ test

$\mathrm{HbO}_{2}=$ Oxyhemoglobin; $\mathrm{VO}_{2}$ max: Maximal oxygen consumption 


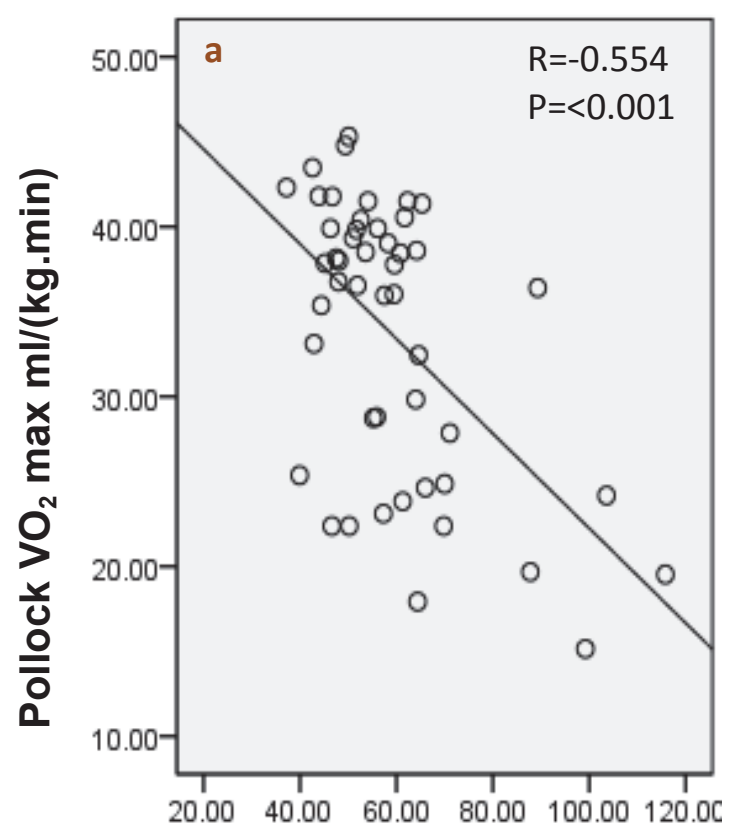

Weight (Kg)

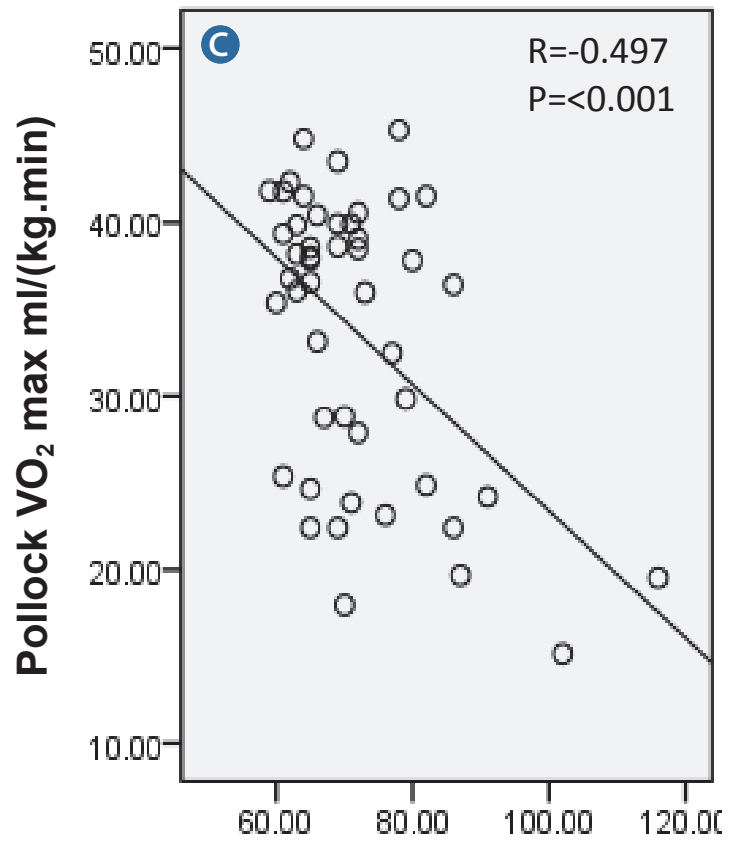

Waist circumference $(\mathrm{cm})$
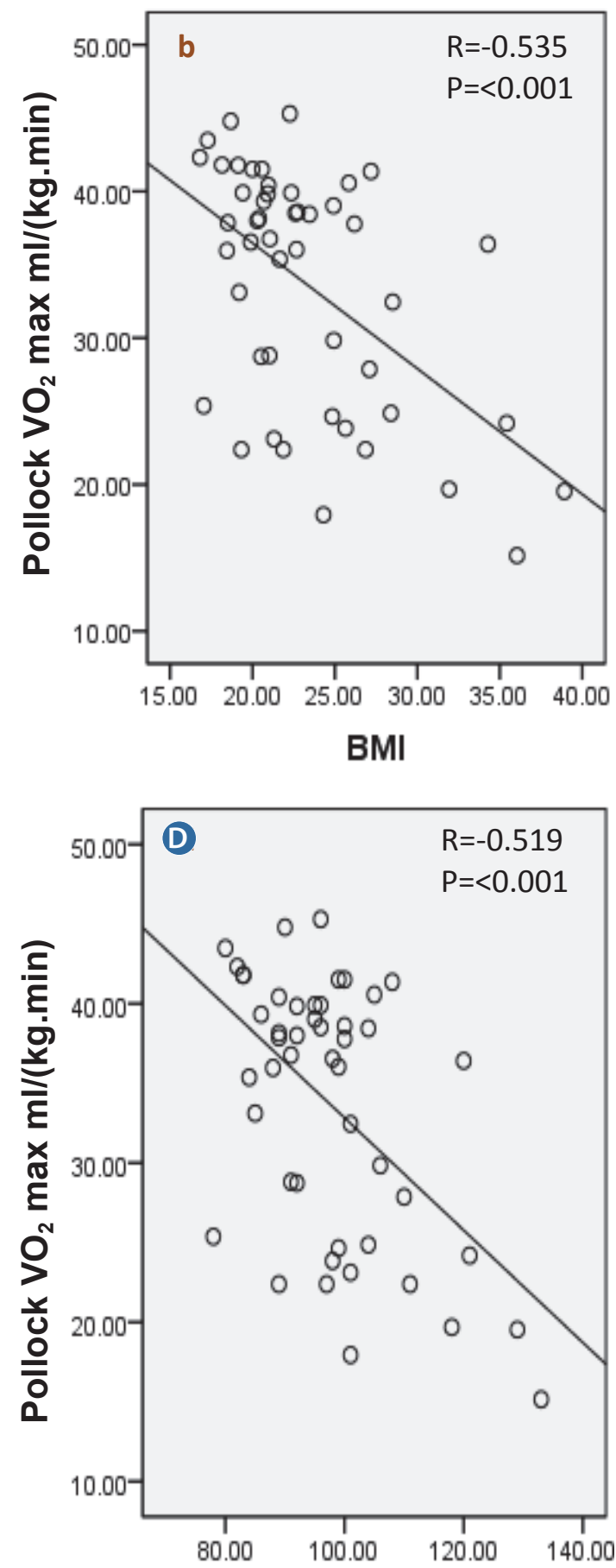

Height circumference $(\mathrm{cm})$

Figure 1. Bivariate correlation and linear regression relationship of $\mathrm{VO}_{2}$ max and anthropometric data: (a) Body weight, (b) BMI, (c) Waist circumference, (d) Hip circumference. 

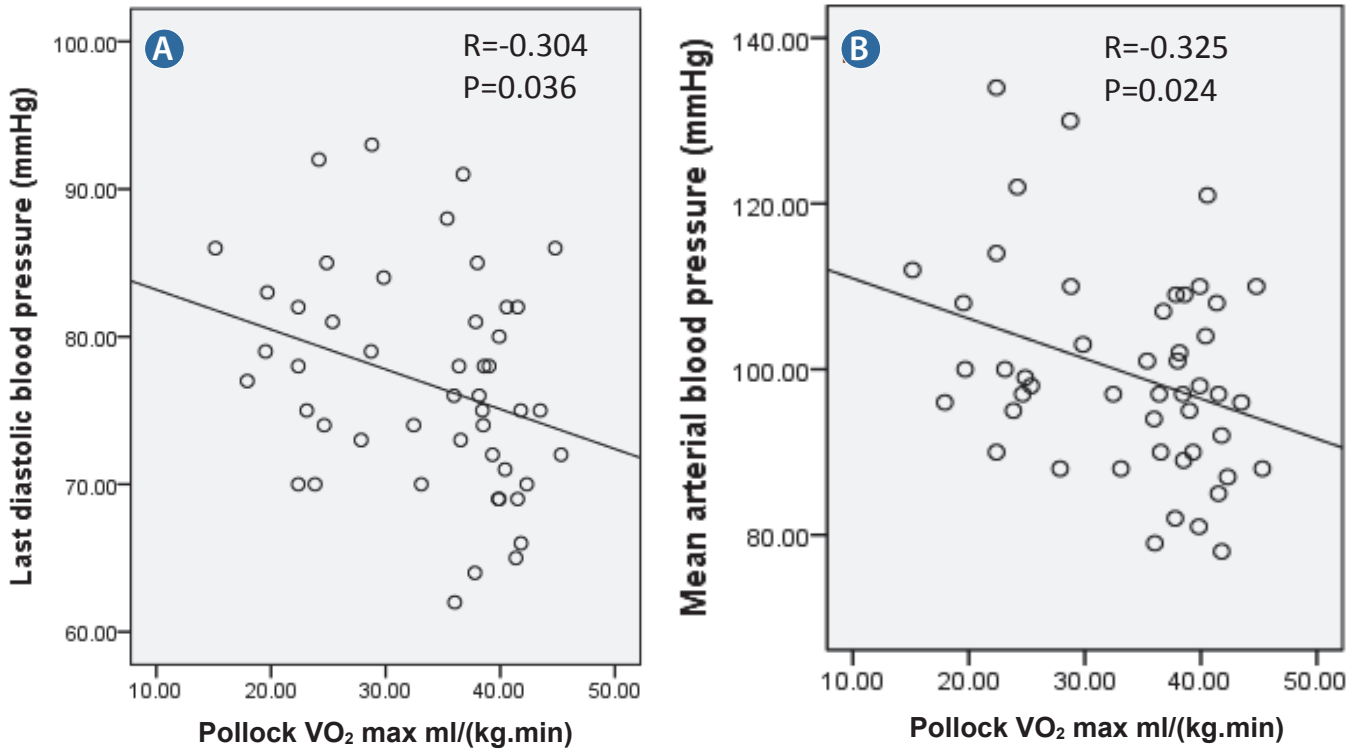

Figure 2. Bivariate correlation and linear regression relationship of $\mathrm{VU}_{2}$ max and Hemodynamic data: (a) Last diastolic blood pressure, (b) Mean arterial blood pressure.

\section{Discussion}

The main finding of the current study is the low $\mathrm{VO}_{2}$ max and time until exhaustion obtained from young Saudi females. $37.50 \%$ of the currently recruited Saudi females were at the category of fair or below based on the classification of the physical fitness specialist certification manual[16]. To our knowledge, this is the first Saudi study that determines $\mathrm{VO}_{2}$ max in young females.

The current findings indicate first, an objective and reliable estimate of the cardiopulmonary fitness status of young Saudi females, since these data were obtained by standard exercise stress test ${ }^{[8]}$. When the value of $\mathrm{VO}_{2}$ max of our studied group was compared to the international value obtained from a large European study, it displays a generalized reduction in the indicator of cardiopulmonary fitness in young Saudi females, $33.6 \pm 8.2 \mathrm{~mL} /(\mathrm{kg} \cdot \mathrm{min})$ compared to $42.8 \pm 7.6 \mathrm{~mL} /(\mathrm{kg} \cdot \mathrm{min})$ from 92 females age $20-29$ of HUNT fitness study ${ }^{[9]}$. Similarly, in a study performed on college female students in Spain, $\mathrm{VO}_{2}$ max of the studied sample was $41.25 \pm 8.5 \mathrm{~mL} /(\mathrm{kg} \cdot \mathrm{min})$ for nonhealth colleges and $35.7 \pm 7.4 \mathrm{~mL} /(\mathrm{kg} \cdot \mathrm{min})$ for nursing students ${ }^{[17]}$. A small study of the aerobic capacity of Mexican-American individuals revealed $\mathrm{VO}_{2} \max$ of females equal to $44.69 \mathrm{~mL} /(\mathrm{kg} \cdot \mathrm{min})^{[18]}$. Furthermore, $\mathrm{VO}_{2}$ max determination of Indian college females revealed a value of $35.9 \pm 3.46 \mathrm{~mL} /(\mathrm{kg} \cdot \mathrm{min})^{[19]}$. Variations in the values of physical fitness among different studies might be attributed to the variation in the methodology and techniques used for the determination of $\mathrm{VO}_{2}$ max. However, other important factors might be involved including differences in body mass ${ }^{[20,21]}$, age groups, environmental, and genetic factors ${ }^{[10]}$

In this study the low $\mathrm{VO}_{2}$ max group was found to be characterized by higher $\mathrm{BMI}$, waist and hip circumference, when compared to the high $\mathrm{VO}_{2}$ max group. In addition, significant negative correlations were found between $\mathrm{VO}_{2}$ max and body weight, $\mathrm{BMI}$, waist and hip circumference. Adiposity is reported in the literature as one of the factors that lead to a deterioration of physical fitness. In an observational study in South Korea of young healthy individuals, BMI was negatively correlated with cardiorespiratory fitness ${ }^{[22]}$. Similarly, $\mathrm{VO}_{2}$ max of young healthy Iranian children was adversely correlated with $\mathrm{BMI}$, waist to height ratio, waist circumference and fat mass ${ }^{[23]}$. Besides being a causative factor of reduced physical fitness, increased body adiposity is believed to work adversely with the low physical fitness to cumulatively increase the health burden upon the cardiovascular and metabolic systems ${ }^{[2]}$.

Hemodynamic parameter comparison between resting and maximum exercise values revealed significantly higher maximum exercise systolic, mean blood pressure and heart rate vs. the corresponding resting values. Laukkanen et al. ${ }^{[24]}$ studied the potential risk of exercise blood pressure, heart rate and $\mathrm{VO}_{2}$ max 
to sudden cardiac death in a prospective study and their data revealed weak correlation of the exercise hemodynamic values including SBP at 2 min recovery to cardiac mortality but strong correlation of low $\mathrm{VO}_{2}$ max with sudden cardiac death ${ }^{[24]}$. Studies that reported reference values and normal ranges of exercise heart rate and blood pressure are few. One largescale community-based study in Germany revealed reference values of exercise hemodynamic parameters for 88 young females with normal BMI as maximum SBP $173 \pm 21$, maximum DBP $88 \pm 12$, and maximum HR $171 \pm 13^{[25]}$. Our reported exercise hemodynamic data were slightly lower than the corresponding German reference data, particularly the systolic blood pressure.

Furthermore, the current study revealed higher last mean and diastolic blood pressure in the group of low $\mathrm{VO}_{2}$ max, and negative correlation between $\mathrm{VO}_{2}$ max and last mean and diastolic blood pressure. The increased diastolic and mean arterial blood pressure induced by exercise stress test in the low fitness group might be an early sign of a future risk of developing hypertension ${ }^{[26]}$. Therefore, we might conclude that the stress test is a useful tool to elucidate the risk for future cardiovascular disorders ${ }^{[27]}$. In addition, the strong negative association between $\mathrm{VO}_{2} \max$ and diastolic and mean arterial blood pressure might indicate the importance of physical fitness in regard to cardiovascular risk ${ }^{[28]}$. In this study systolic blood pressure was not elevated or correlated with $\mathrm{VO}_{2}$ max. It might be explained by the structure of the recruited sample i.e., young age group and female only, where the association of high systolic blood pressure and reduced fitness is less frequently developed ${ }^{[29,30]}$

One proposed mechanism of the relationship of reduced physical fitness, increased fat and increased arterial blood pressure is a claimed increase in sympathetic stimulation and improper balance between sympathetic and parasympathetic discharge whether at rest or during exercise ${ }^{[31,32]}$. Improvement in physical fitness is found to be associated with enhancement and a reversing of sympathetic parasympathetic imbalance ${ }^{[33,34]}$.

Last but not least, there was no significant correlation between $\mathrm{VO}_{2}$ max and age. The reason might be due to the relatively small sample size and the narrow age range of the involved sample.

\section{Conclusion}

In conclusion, our cross-sectional study revealed low cardiopulmonary fitness level in young Saudi females indicated by low $\mathrm{VO}_{2}$ max. We assume that increased body fat might be one of the main causative factors for the currently discovered low $\mathrm{VO}_{2}$ max. However, we recommend future studies to reveal other possible underlying mechanisms. Moreover, the currently demonstrated reduced fitness was also associated with high exercise diastolic blood pressure, which might be an initial sign for potential risk of future cardiovascular morbidity. A large national plan is urgently needed to study the physical fitness of different age groups of our population, to increase the awareness of the need for better physical fitness among females in Saudi Arabia and to provide opportunities to enhance the fitness in schools, educational institutes, community and recreational centers.

\section{Limitations}

The current study might be limited by the relatively small sample size and the narrow age group. Based on the obtained data from young educated Saudi females, we believe large national studies of the female population of different age and cultural groups are highly recommended. However, the current obtained data would serve as a good reference and baseline data for future studies.

\section{Acknowledgment}

I would like to thank Ms. Amal Algemlas for her assistance in data collection. The project was executed by Grant number 2013183 provided by the Deanship of Scientific Research at University of Dammam, Dammam, Saudi Arabia.

\section{Conflict of Interest}

The author has no conflict of interest.

\section{Disclosure}

The author did not received any type of commercial support either in forms of compensation or financial for this study. The author has no financial interest in any of the products or devices, or drugs mentioned in this article.

\section{Ethical Approval}

Obtained

\section{References}

[1] Barry VW, Baruth M, Beets MW, Durstine JL, Liu J, Blair SN Fitness vs. fatness on all-cause mortality: a meta-analysis. Prog Cardiovasc Dis 2014; 56(4): 382-390. 
[2] Twisk JW, Kemper HC, van Mechelen W. Tracking of activity and fitness and the relationship with cardiovascular disease risk factors. Med Sci Sports Exerc 2000; 32(8): 1455-1461.

[3] Al-Hazzaa HM. Health-enhancing physical activity among Saudi adults using the International Physical Activity Questionnaire (IPAQ). Public Health Nutr 2007; 10(1): 59-64.

[4] Taha AZ. Self-reported knowledge and pattern of physical activity among school students in Al Khobar, Saudi Arabia. East Mediterr Health J 2008; 14(2): 344-355.

[5] Al-Hazzaa HM, Alahmadi MA, Al-Sobayel HI, Abahussain NA, Qahwaji DM, Musaiger AO. Patterns and determinants of physical activity among saudi adolescents. J Phys Act Health 2014; 11(6): 1202-1211.

[6] Al-Rafaee SA, Al-Hazzaa HM. Physical activity profile of adult males in Riyadh City. Saudi Med J 2001; 22(9): 784 789.

[7] Bermúdez VJ, Rojas JJ, Córdova EB, Añez R, Toledo A, Aguirre MA, Cano C, Arraiz N, Velasco M,López-Miranda J. International physical activity questionnaire overestimation is ameliorated by individual analysis of the scores. Am J Ther 2013; 20(4): 448-458.

[8] Ross RM. ATS/ACCP statement on cardiopulmonary exercise testing. Am J Respir Crit Care Med 2003; 167(10): 1451

[9] Loe H, Steinshamn S, Wisløff U. Cardio-respiratory reference data in 4631 healthy men and women 20-90 years: the HUNT 3 fitness study. PLoS One 2014; 9(11): e113884.

[10] Koch B, Schäper C, Ittermann T, Spielhagen T, Dörr M Völzke H, Opitz CF, Ewert R, Gläser S. Reference values for cardiopulmonary exercise testing in healthy volunteers: the SHIP study. Eur Respir J 2009; 33(2): 389-397.

[11] Association WM. World Medical Association Declaration of Helsinki: ethical principles for medical research involving human subjects. JAMA 2013; 310(20): 2191-2194.

[12] FroelicherVF, Thompson AJ, Davis G, Stewart AJ, Triebwasser $\mathrm{JH}$. Prediction of maximal oxygen consumption. Comparison of the Bruce and Balke treadmill protocols Chest. 1975; 68(3): 331-336.

[13] Tanaka H, Monahan KD, Seals DR. Age-predicted maximal heart rate revisited. J Am Coll Cardiol 2001; 37(1): 153-156.

[14] Pollock ML, Foster C, Schmidt D, Hellman C, Linnerud AC, Ward A. Comparative analysis of physiologic responses to three different maximal graded exercise test protocols in healthy women. Am Heart J 1982; 103(3): 363-373.

[15] Palaniappan $L$, Simons LA, Simons J, Friedlander $Y$, McCallum J. Comparison of usefulness of systolic, diastolic, and mean blood pressure and pulse pressure as predictors of cardiovascular death in patients $>/=60$ years of age (The Dubbo Study). Am J Cardiol 2002; 90(12): 1398-1401.

[16] Heyward VH.. Advance Fitness Assessment and Exercise Prescription. 6th ed. Thomas-Shore, Inc. 2010
[17] Irazusta A, Gil S, Ruiz F, Gondra J, Jauregi A, Irazusta J, Gi J. Exercise, physical fitness, and dietary habits of first-year female nursing students. Biol Res Nurs 2006; 7(3): 175-186.

[18] Pennathur A, Lopes A, Contreras LR. Aerobic capacity of young Mexican American adults. Int J Industrial Ergonomics 2004; 35(1): 105-117.

[19] Varghese MA, Saha PN, Atreya N. Aerobic capacity of urban women homemakers in Bombay. Ergonomics 1995; 38(9): 1877-1883.

[20] Voss C, Sandercock G, Wharf Higgins J, Macdonald H, Nettlefold L, Naylor PJ, McKay H. A cross-cultural comparison of body composition, physical fitness and physical activity between regional samples of Canadian and English children and adolescents. Can J Public Health 2014; 105(4): e245-250.

[21] Tompuri T, Lintu N, Savonen K, Laitinen T, Laaksonen D, Jääskeläinen J, Lakka TA. Measures of cardiorespiratory fitness in relation to measures of body size and composition among children. Clin Physiol Funct Imaging 2015; 35(6): 469-477.

[22] So WY, Choi DH. Differences in Physical Fitness and Cardiovascular Function Depend on BMI in Korean Men. J Sports Sci Med 2010; 9(2): 239-244

[23] Esmaeilzadeh S, Kalantari H, Nakhostin-Roohi B. Cardiorespiratory fitness, activity level, health-related anthropometric variables, sedentary behaviour and socioeconomic status in a sample of Iranian 7-11 year old boys. Biol Sport 2013; 30(1): 67-71.

[24] Laukkanen JA, Rauramaa R. Systolic blood pressure during exercise testing and the risk of sudden cardiac death. Int Cardiol 2013; 168(3): 3046-3047.

[25] Gläser S, Friedrich N, Koch B, Schäper C, Völzke H, Felix SB, et al. Exercise blood pressure and heart rate reference values. Heart Lung Circ 2013; 22(8): 661-667.

[26] Mariampillai JE, Engeseth K, Kjeldsen SE, Grundvold I, Liestø| K, Erikssen G, Erikssen JE, Bodegård J,Skretteberg PT. 2D.01: Exercise systolic blood pressure $>/=190 \mathrm{mmhg}$ at moderate workload predicts coronary heart disease in healthy, middle-aged men. J Hypertens 2015; 33 Suppl 1 : e28.

[27] Kjeldsen SE, Mundal R, Sandvik L, Erikssen G, Thaulow E, Erikssen J. Exercise blood pressure predicts cardiovascular death and myocardial infarction. Blood Press Monit 1997; 2(3): 147-153.

[28] Gondim OS, Camargo VT, Gutierrez FA, Martins PF, Passos ME, Momesso CM, Santos VC, Gorjão R, Pithon-Curi TC, Cury-Boaventura MF. Benefits of regular exercise on inflammatory and cardiovascular risk markers in normal weight, overweight and obese adults. PLoS One 2015; 10(10): e0140596.

[29] Tan S, Wang J, Zhang Y, Zhang C. Associations between 
objectively measured physical activity, cardiorespiratory fitness and risk factors for metabolic syndrome in 12- to 15-year old Tianjin city children. Health Educ J 2015; 74(4): 403-410.

[30] Hurtig-Wennlöf A, Ruiz JR, Harro M, Sjöström M. Cardiorespiratory fitness relates more strongly than physical activity to cardiovascular disease risk factors in healthy children and adolescents: the European Youth Heart Study. Eur J Cardiovasc Prev Rehabil 2007; 14(4): 575581.

[31] Indumathy J, Pal GK, Pal P, Ananthanarayanan PH, Parija SC, Balachander J, Dutta TK. Association of sympathovagal imbalance with obesity indices, and abnormal metabolic biomarkers and cardiovascular parameters. Obes Res Clin Pract 2015; 9(1): 55-66

[32] Pal GK, Adithan C, Dutta TK, Pal P, Nanda N, Lalitha V, Syamsunder AN. Association of hypertension status and cardiovascular risks with sympathovagal imbalance in first degree relatives of type 2 diabetics. J Diabetes Investig 2014; 5(4): 449-455.

[33] Wong A, Figueroa A. Eight weeks of stretching training reduces aortic wave reflection magnitude and blood pressure in obese postmenopausal women. J Hum Hypertens 2014; 28(4): 246-250.

[34] Goulopoulou S, Baynard T, Franklin RM, Fernhall B, Carhart $\mathrm{R} J \mathrm{~J}$, Weinstock R, Kanaley JA. Exercise training improves cardiovascular autonomic modulation in response to glucose ingestion in obese adults with and without type 2 diabetes mellitus. Metabolism 2010; 59(6): 901-910. 


\title{
هل معدل اللياقة البذنية لاى السيدات الثشابات في المملكة العربية السعودية يشكل مصدر خطر صحي لثهن
}

\author{
لبنى إبراهيم عبدالعزيز العسوم

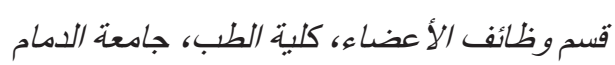

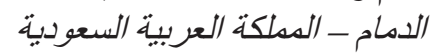

المستخلص. يعد انخفاض اللياقة البدنية إحدى عو امل الخطورة للإصابة بأمر اض القلب والثر ايين ومتلازمة الاعتلال الأيضي. لذا نود في هذا البحث دراسة معدل اللياقة البدنية لدى السيدات السعوديات الثابات ودراسة العلاقة بين هذا المعدل ومعايير البدانة ومؤشر ات الجهاز الدوري.

تم جمع عينة من ^^ طالبة من جامعة الدمام خضعن لاختبار الجهد البدني الأقصى وتم قياس المؤشر ات الحيوية للجهاز الدوري كمعدل

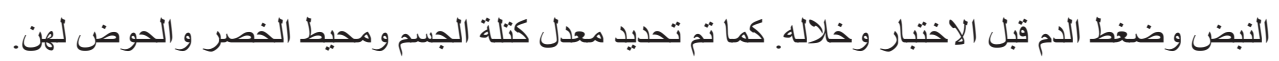

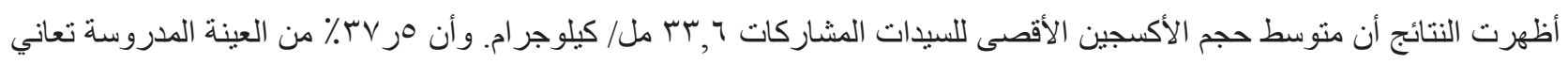

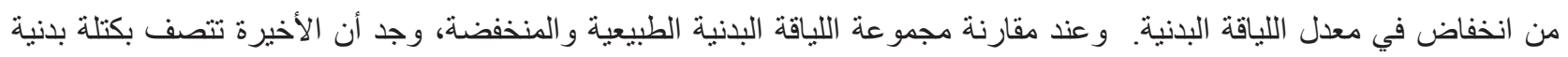

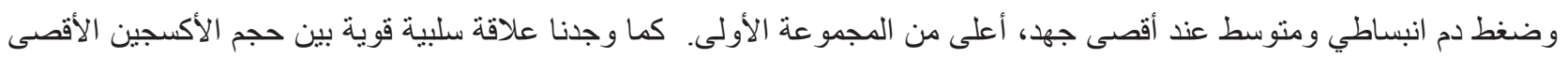
ومعدل كتلة الجسم وضغط الدم الانبساطي و المتوسط عند أعلى جهد.

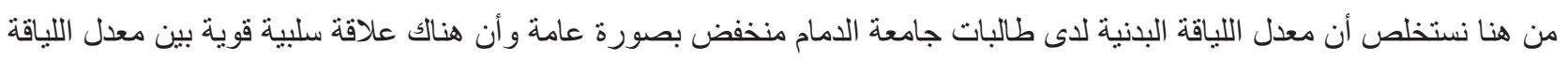

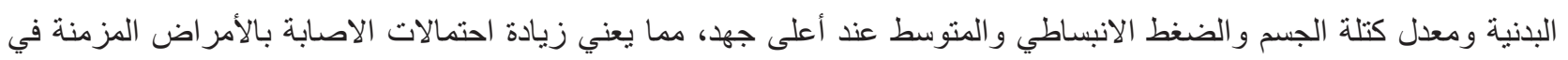
المستقبل و هذا يستلزم زيادة الوعي ودر اسة أسباب الانخفاض وأخذ تدابير وقائية لرفع مستوى اللياقة البدنية لاى النساء في السعودية. 